\title{
Визуализация двух видов свечения в акустическом поле в жидкости
}

\author{
(ㄷ Г.Л. Шарипов, А.М. Абдрахманов, Б.М. Гареев \\ Институт нефртехимии и катализа, Уфимский федеральный исследовательский центр РАН, Уфа, Россия \\ E-mail: glus@anrb.ru
}

Поступило в Редакцию 5 июля 2019г.

В окончательной редакции 5 июля 2019г.

Принято к публикации 6 августа 2019г.

Получены фотографии и спектры однопузырьковой сонолюминесценции движущегося пузырька в чистой воде и водных растворах $\mathrm{Ru}(\mathrm{bpy})_{3}^{2+}$. Для растворов комплекса рутения показано наличие зон свечения, расположенных вне линии основной траектории движения светящегося пузырька, характерной для чистой воды. Наблюдаемая пространственная локализация данных зон подтверждает обусловленность их появления, как ранее было показано авторами, сонохемилюминесценцией комплекса рутения в объеме раствора, вторичной относительно первичной сонолюминесценции самого пузырька.

Ключевые слова: однопузырьковая сонолюминесценция, сонохемилюминесценция, визуализация, комплекс $\mathrm{Ru}(\mathrm{bpy})_{3}^{2+}$.

DOI: 10.21883/PJTF.2019.23.48710.17965

Свечение в жидкостях, наблюдаемое при воздействии акустических (обычно ультразвуковых) волн, известно с 1934 г. Причиной этого свечения является образование кавитационных газонаполненных пузырьков, которые пульсируют в жидкости, расширяясь и сжимаясь с частотой акустических колебаний. На конечной стадии циклов сжатия содержимое пузырьков разогревается до тысяч и даже десятков тысяч градусов и при столкновениях горячих частиц некоторая часть их энергии излучается в виде вспышек света, называемого сонолюминесценцией (СЛ) [1]. Наряду со свечением пузырьков могут иметь место и другие виды явления излучения света, индуцируемого акустическим воздействием. Так, при наличии в жидкости молекул или ионов люминофоров имеет место сонофотолюминесценция (СФЛ) [2]. Это переизлучение части свечения пузырьков, поглощенного люминофорами в объеме жидкости. Интенсивность СФЛ меньше интенсивности первичной СЛ пузырьков, а ее спектральный состав отличен от спектра СЛ. В некоторых растворах люминофоров может возникнуть и другой вид вторичного по отношению к излучению света пузырьками свечения, а именно сонохемилюминесценция (СХЛ) [3]. Она появляется в результате химических реакций первичных продуктов сонолиза (разложения) молекул жидкости, образуемых в кавитационных пузырьках и выходящих в объем жидкости, с люминофорами. Например, в водных растворах это хемилюминесцентные реакции Н и ОН с люминолом [4], соединениями $\mathrm{Tb}^{3+}$ [5] и $\mathrm{Ru}^{2+}$ [6]. Спектральный состав СХЛ также отличен от спектра первичной СЛ, а интенсивность СХЛ может быть даже выше интенсивности СЛ [7].

Кроме различий в спектрах и интенсивностях первичного и вторичных видов индуцируемого акустическим воздействием свечения интересным является вопрос пространственной локализации этих видов, подтверждающий изложенные особенности механизмов их воз- никновения. В случае многопузырьковой СЛ при наличии облака, состоящего из сотен и тысяч движущихся пузырьков, различить локализации первичного и вторичного свечений затруднительно. Однако это может быть осуществимо в случае однопузырьковой СЛ (ОПСЛ), когда имеет место свечение одиночного пузырька, левитирующего в пучности стоячей ультразвуковой волны. Настоящая работа посвящена реализации данной возможности путем фотографической регистрации картины ОПСЛ воды и однопузырьковой сонохемилюминесценции (ОПСХЛ) водного раствора комплекса рутения $\mathrm{Ru}(\mathrm{bpy})_{3} \mathrm{Cl}_{2}$, далее для краткости обозначаемого также как $\mathrm{Ru}(\mathrm{II})$.

B растворе данного комплекса ион $\mathrm{Ru}(\mathrm{bpy})_{3}^{2+}$ является люминофором, и для него существует СФЛ. Однако квантовый выход его фотолюминесценции не очень высок: не более 5\% в воде [8]. Поэтому вклад СФЛ в общую интенсивность свечения раствора $\mathrm{Ru}(\mathrm{II})$ мал и хорошо заметен при однопузырьковом сонолизе только в том случае, когда пульсирующий пузырек неподвижен [9]. Такой режим реализуется при акустическом давлении $p_{a}$ в центре резонатора, где левитирует пузырек, около 1.2 bar. При повышении $p_{a}$ до 1.3 bar становится доминирующим другой вид вторичного свечения $\mathrm{Ru}(\mathrm{II})-$ ОПСХЛ [9]. В этом случае пузырек совершает трансляционные движения возле центра стабилизации, неоднократно меняя направление вектора перемещения. При этом граница раздела между пузырьком и жидкостью деформируется, возникают поверхностные волны и струи жидкости, инжектирующие мельчайшие капли раствора в объем пузырька [10]. В случае неподвижного пузырька граница раздела является сферически-симметричной, и поступление раствора в пузырек путем обычного испарения малоэффективно. В режиме движущегося пузырька, обозначаемого ОПСЛ-РД, наряду с массопереносом из жидкости в пузырек интенсифицируется 


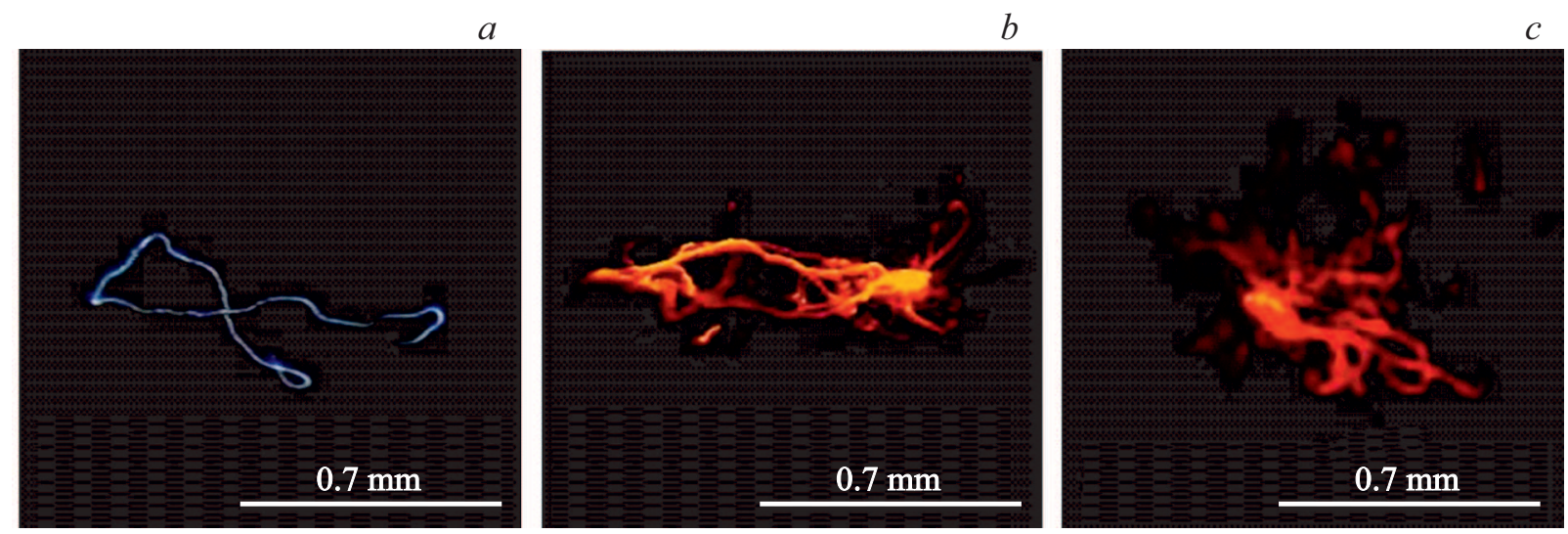

Рис. 1. Фотографии однопузырьковой сонолюминесценции движущегося пузырька при $p_{a}=1.32$ bar. $a-$ вода, $b$ и $c-$ водный раствор $\mathrm{Ru}(\mathrm{bpy})_{3}^{2+}\left(5 \cdot 10^{-6}\right.$ и $10^{-5} \mathrm{M}$ соответственно). Экспозиция на снимках $1 \mathrm{~s}$, частота ультразвука $27.3 \mathrm{kHz}$, снимки сделаны цифровым фотоаппаратом Nicon D3000.

и обратный процесс массопереноса пузырек-жидкость. В результате в жидкости возникают продукты сонолиза молекул воды Н и ОН, а по полученным нами последним данным также и гидратированные электроны $e_{a q}$ [9]. $\mathrm{B}$ реакциях с $\mathrm{H}$ и $e_{a q}$ комплекс $\mathrm{Ru}(\mathrm{II})$ восстанавливается до $\mathrm{Ru}(\mathrm{I})$, а взаимодействуя с радикалом $\mathrm{OH}$, окисляется до $\mathrm{Ru}(\mathrm{III})$. Далее интенсивная ОПСХЛ возникает в реакциях $\mathrm{Ru}(\mathrm{III})+\mathrm{Ru}(\mathrm{I}) \rightarrow{ }^{*} \mathrm{Ru}(\mathrm{II})+\mathrm{Ru}(\mathrm{II})$, $\mathrm{Ru}(\mathrm{III})+e_{a q} \rightarrow{ }^{*} \mathrm{Ru}(\mathrm{II}),{ }^{*} \mathrm{Ru}(\mathrm{II}) \rightarrow \mathrm{Ru}(\mathrm{II})+h v$ [9]. Очевидно, являясь вторичным свечением, ОПСХЛ должна быть пространственно локализована вне пузырька.

На рис. 1, а приведена фотография траектории пузырька при ОПСЛ-РД в чистой воде, полученная в свете его собственного свечения. Траектория представляет собой четко очерченную линию толщиной около $20 \mu \mathrm{m}$. Это близко к величине минимального диаметра неподвижного пульсирующего пузырька [11]. Реальный диаметр светящейся области, возникающей при максимальном сжатии такого сферического пузырька, должен быть еще меньше, однако наблюдаемая толщина траектории движущегося пузырька должна определяться также наличием деформаций пузырька и его смещениями относительно основной оси движения во время многочисленных, сливающихся в траекторию вспышек. Траектория обладает бело-голубой окраской благодаря многоэмиттерному континууму свечения пузырька в широкой области спектра, показанному на рис. 2 (кривая 1). Коротковолновая граница данного спектра обусловлена поглощением ультрафиолетовой части континуума стеклянной стенкой колбы-резонатора для наблюдения ОПСЛ. На рис. $1, b$ приведена фотография той же траектории в растворе $5 \cdot 10^{-6} \mathrm{M} \mathrm{Ru}(\mathrm{bpy})_{3}^{2+}$. Данная траектория обладает оранжевой окраской, видной на фотографии в электронном варианте статьи, благодаря появлению в спектре свечения полосы комплекса $\mathrm{Ru}(\mathrm{II})$ с максимумом в районе $613 \mathrm{~nm}$ (рис. 2, кривая 2). Но самое главное, наряду с линией движения пузырька, подобной линии в чистой воде, на фотографии хоро- шо заметно наличие примыкающих к ней диффузных размытых областей свечения различной формы. Такие области отсутствуют на рис. 1, $a$. По нашему мнению, диффузные области свечения представляют собой визуализированные светом хемилюминесцентных реакций микроструи продуктов сонолиза, инжектируемые из пузырька в объем раствора при его движениях. Окраска не только этих областей, но и самой линии движения пузырька в оранжевый цвет, обусловленный люминесценцией $\mathrm{Ru}(\mathrm{II})$, вызвана тем, что наиболее интенсивная хемилюминесценция имеет место в области наиболее высоких локальных концентраций продуктов сонолиза, т.е. практически непосредственно на границе раздела пузырек-жидкость. Еще большее диффузное размытие линии траектории движения пузырька заметно в растворе $10^{-5} \mathrm{M} \mathrm{Ru}(\text { bpy })_{3}^{2+}$ (рис. 1, c), в спектре которого растет интенсивность полосы $\mathrm{Ru}(\mathrm{II})$ (рис. 2, кривая 3). Исчезновение четкой линии траектории пузырька при

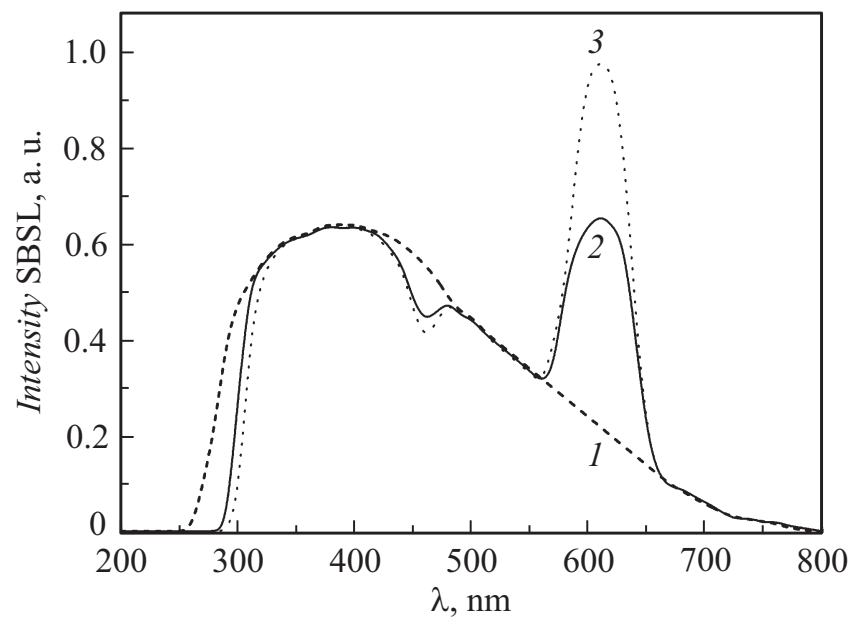

Рис. 2. Спектры однопузырьковой сонолюминесценции движущегося пузырька при $p_{a}=1.32$ bar. $1-$ вода, 2 и $3-$ водный раствор $\mathrm{Ru}(\mathrm{bpy})_{3}^{2+}\left(5 \cdot 10^{-6}\right.$ и $10^{-5} \mathrm{M}$ соответственно). 
увеличении концентрации $\mathrm{Ru}(\mathrm{II})$ и замещение ее диффузными областями свечения, охватывающими гораздо бо́льшую часть объема раствора, даже лучше визуализируются на черно-белых копиях фотографий, приводимых в бумажной версии статьи.

Таким образом, в водном растворе $\mathrm{Ru}(\mathrm{bpy})_{3}^{2+}$ визуализировано наличие зон свечения, расположенных вне линии основной траектории движения светящегося пузырька, характерной для чистой воды. Наблюдаемая пространственная локализация данных зон подтверждает обусловленность их появления, как было показано ранее $[6,9]$, сонохемилюминесценцией комплекса рутения в объеме раствора, вторичной относительно первичной сонолюминесценции самого пузырька.

\section{Финансирование работы}

Работа выполнена в рамках государственного задания № AAAA-A19-119022290005-5.

\section{Конфликт интересов}

Авторы заявляют, что у них нет конфликта интересов.

\section{Список литературы}

[1] Маргулис М.А. // УФН. 2000. Т. 170. С. 263-287.

[2] Ashokkumar M., Grieser F. // Ultrason. Sonochem. 1999. V. 6. P. 1-5. DOI: $10.1016 / \mathrm{S} 1350-4177(98) 00038-8$

[3] Harvey E.N. // J. Am. Chem. Soc. 1939. V. 61. P. 2392-2398.

[4] Taylor K.J., Jarman P.D. // J. Am. Chem. Soc. 1971. V. 93. P. 257-258. DOI: $10.1021 / \mathrm{ja} 00730 \mathrm{a} 047$

[5] Kulmala S., Ala-Kleme T., Latva M., Haapakka K., Hakanen A. // J. Chem. Soc. Faraday Trans. 1996. V. 92. P. 2529-2533. DOI: 10.1039/FT9969202529

[6] Sharipov G.L., Abdrakhmanov A.M., Gareev B.M., Yakshembetova L.R. // Ultrason. Sonochem. 2018. V. 42. P. 526-530. DOI: 10.1016/j.ultsonch.2017.12.013

[7] Dharmarathne L., Ashokkumar M., Grieser F. // J. Phys. Chem. C. 2012. V. 116. P. 1056-1060.

DOI: $10.1021 /$ jp209946s

[8] Kalyanasundaram K. // Coord. Chem. Rev. 1982. V. 46. P. $159-244$.

[9] Gareev B.M., Yakshembetova L.R., Abdrakhmanov A.M., Sharipov G.L. // J. Lumin. 2019. V. 208. P. 99-103. DOI: 10.1016/j.jlumin.2018.12.033

[10] Xu H., Eddingsaas N.C., Suslick K.S. // J. Am. Chem. Soc. 2009. V. 131. P. 6060-6061. DOI: $10.1021 / j a 900457 \mathrm{v}$

[11] Brenner M.P., Hilgenfeldt S., Lohse D. // Rev. Mod. Phys. 2002. V. 74. P. 425-484. 